EPV007/\#582 DNA DAMAGE REPAIR IS ALTERED BY INHIBITION OF DISCOIDIN DOMAIN RECEPTOR 2 (DDR2) THROUGH METABOLIC REWIRING IN HOMOLOGOUS-RECOMBINATION PROFICIENT OVARIAN CANCER MODELS

${ }^{1}$ E Stock* ${ }^{2} \mathrm{~K}$ Cho, ${ }^{1} \mathrm{E}$ Lomonosova, ${ }^{1} \mathrm{~A}$ Schab, ${ }^{1} \mathrm{~A}$ Oplt, ${ }^{1} \mathrm{H}$ Noia, ${ }^{1} \mathrm{~S}$ Bruce, ${ }^{1} \mathrm{D}$ Khabele, ${ }^{1}$ L Kuroki, ${ }^{1} \mathrm{~A}$ Hagemann, ${ }^{1} \mathrm{C}$ Mccourt, ${ }^{1} \mathrm{P}$ Thaker, ${ }^{1} \mathrm{D}$ Mutch, ${ }^{1} \mathrm{M}$ Powell, ${ }^{2} \mathrm{~L}$ Shriver, ${ }^{2} \mathrm{G}$ Patti, ${ }^{1} \mathrm{~K}$ Fuh. 'Washington University, Gynecologic Oncology, St. Louis, USA; ${ }^{2}$ Washington University School of Medicine, Department of Chemistry, St. Louis, USA

\subsection{6/ijgc-2021-IGCS.74}

Objectives Discoidin Domain Receptor 2 (DDR2) is a receptor tyrosine kinase which binds fibrillar collagen. Previous work from our lab demonstrated that DDR2 inhibition increases sensitivity to olaparib in homologous recombination (HR) proficient ovarian cancer. This study aimed to understand the mechanism of DDR2 inhibition increasing sensitivity to olaparib.

Methods Three DDR2-expressing human ovarian cancer cell lines, ES2, COV362, and PEO4, with short hairpin control and DDR2 knockdowns were used. The HR status after irradiation and DNA damage response after treatment with olaparib was determined using immunofluorescence. In vivo metabolomics analysis of ES2 tumors was performed after injection of U-13C-glucose tracer.

Results All cell lines had a 2-fold increase in RAD51 foci after irradiation indicating HR proficiency. DDR2 knockdown induced HR deficiency. To confirm that DDR2 regulated HR, DDR2 knockdown cells were rescued with DDR2 wild-type (DDR2-WT rescue) in order to re-express DDR2. DDR2-WT rescue cells were again HR proficient. On western, BRCA1 expression was decreased in cells without DDR2 expression through decreased activation of the PI3K pathway. Knockdown of DDR2 increased DNA damage and repair through nonhomologous end-joining both at baseline and after treatment with olaparib. These findings reversed in DDR2-WT rescue cells. In vivo metabolomics analysis of tumors without DDR2 expression found decreased pentose phosphate pathway activation including decreased ribose-5-phsophate, an intermediate essential for DNA repair through nucleotide biosynthesis.

Conclusions DDR2 inactivation sensitizes HR proficient ovarian cancer cells to olaparib through induced HR deficiency and metabolic rewiring possibly leading to impaired DNA damage repair. Current experiments are underway to confirm metabolomics findings.

\section{EPV008/\#139 ROLE OF KI67 IN PREDICTING SURVIVAL IN RH+/ HER2- BREAST CANCER ACCORDING TO AXILLARY NODAL INVOLVEMENT}

N Mejir, Y Berrazega*, H Rachdi, I Harhira, H Boussen. University hospital Abderrahmen Mami Ariana, Medical Oncology, Tunis, Tunisia

10.1136/ijgc-2021-IGCS.75

Objectives We aimed to evaluate the cut-off value of Ki67 that predicted survival in luminal breast cancer and investigated its survival impact according to axillary lymph node involvement.

Methods We retrospectively selected 321 cases of histologically confirmed, early stage, breast cancer treated between 2011-
2015. All patients had ER and/or PR positive (>10\% expression) and HER2- tumors. We evaluated the prognostic value of several cut-off levels of Ki67 in terms overall survival (5year OS): 14\%, 20\%, 30\% and 50\%. We also considered different subgroups according to axillary lymph node involvement: pN0(38\%), $1-3 \mathrm{pN}+(35 \%)$ and $\geq 4 \mathrm{pN}+(27 \%)$. We used Kaplan Meier method and Cox regression models to evaluate survival.

Results Median age was 49 years-old, 42\% were menopausal. Media Ki67 was 28\%. Sixty four percent of patients had mastectomy, 93\% received chemotherapy and $88 \%$ radiation therapy. On overall population, after median follow-up of 51 months, we observed a significant difference in OS only with the Ki67 cut-off of $30 \% \quad(67$ vs 64 months, $\mathrm{p}=0.04$, $\mathrm{HR}=0.79 \mathrm{IC}$ à 95\% [0.6-0.87]). In node negative $\mathrm{pN} 0 \mathrm{popu}-$ lation, Ki67 cut-off $=20 \%$ was significantly associated with OS (72 vs 65 months, $\mathrm{p}=0.03, \mathrm{HR}=0.83$ [0.63-0.92]). In node positive tumours different Ki 67 cut-off values did not predict survival except in $\geq 4 \mathrm{pN}+$ group, where patients with Ki67 $>50 \%$ had significantly worse OS compared to patients $\leq 50 \%$ (63 vs 30 months, $\mathrm{p}=0.01, \mathrm{HR}=0.31$ IC à 95\% [0.22-0.65]).

Conclusions Ki67 level in RH+/HER2- breast cancer predicted survival with the cut-off value of $30 \%$. Ki67 had an impact on survival with a cut-off $=20 \%$ in node negative and $50 \%$ in $\geq 4 \mathrm{pN}+$ tumours.

\section{EPV009/\#143 MAGNETIC RESONANCE ACCURACY IN DIAGNOSING THE SIZE OF DUCTAL CARCINOMA IN SITU - PRELIMINARY RESULTS OF A SYSTEMATIC REVIEW AND META-ANALYSES}

${ }^{1} \mathrm{M}$ Robalo Cordeiro*, ${ }^{2} \mathrm{R}$ Roque, ${ }^{1} \mathrm{M}$ Figueiredo-Dias. ${ }^{1}$ University Hospital Center of Coimbra, Gynecology Department, Coimbra, Portugal; ${ }^{2}$ Portuguese Institute of Oncology Coimbra, Medical Oncology Department, Coimbra, Portugal

\subsection{6/ijgc-2021-IGCS.76}

Objectives To evaluate the accuracy of Magnetic Resonance Imaging (MRI) in measuring the pure Ductal Carcinoma In Situ (DCIS) size, against pathology, to better understand the MRI role in the management of this non-invasive intraductal breast neoplasm.

Methods Potential eligible studies in MEDLINE, Embase and Google Scholar, until January-2021 were considered, and systematic review and meta-analysis according to the published protocol (Prospero - CRD42021232228) was performed. Outcomes of mean differences and accuracy rates using IBM $^{\circledR}$ SPSS $^{\circledR}$ v26 and random-effect model in platform $\mathrm{R}$ v3.3.2 were analysed.

Results Twenty-two cross-sectional studies were selected and 15 proceeded to meta-analyses. MRI accurately predicted $55 \%$ of tumours size and according to Bland-Altman plots, concordance between MRI and pathology was greater for smaller tumours. In meta-analyses, the difference of the means between MRI and pathology is $3.85 \mathrm{~mm}$ (CI95\% [-0.92;8.60]) with considerable heterogeneity (I2=96.7\%). Subgroup analyses showed similar effect sizes between different MRI fields, acquisition times and contrasts, but lower heterogeneity in studies using Gadolinium $(\mathrm{I} 2=48.7 \%)$ and 3-Tesla MRI (I2 $=57.2 \%)$. Results were concordant in low risk of bias 
studies $(2.46$, CI95\% [0.57-4.36]), without detected heterogeneity $(\mathrm{I} 2=0 \%)$.

Conclusions MRI is an accurate method in pure DCIS size assessment. Once the best MRI protocol is established, evaluation of the impact of pure DCIS size in predicting treatment outcomes will contribute to clarify intraductal breast carcinoma current issues.

\section{EPV010/\#168 INFLAMMATORY BREAST CANCER PARTICULARITIES IN TUNISIAN PATIENTS}

${ }^{1} \mathrm{~A}$ Zribi, ${ }^{1} \mathrm{~S}$ Ben Nasr, ${ }^{1} \mathrm{M}$ Ahmad, ${ }^{2} S$ Fendri, ${ }^{1} \mathrm{~N}$ Mansouri, ${ }^{2} \mathrm{R}$ Arfaoui ${ }^{*},{ }^{1}$ I Mejri, ${ }^{2} \mathrm{M}$ Balti, ${ }^{2}$ A Haddaoui. ${ }^{1}$ oncologymilitary hospital of Tunis, Oncology, Tunis, Tunisia; ${ }^{2}$ military hospital of Tunis, Oncology, Tunis, Tunisia

\subsection{6/ijgc-2021-IGCS.77}

Objectives Inflammatory breast cancer (IBC) accounts for 5 to $7 \%$ of breast cancers in Tunisia. The objective of our study was to report the therapeutic results as well as the prognostic factors of this entity.

Methods We conducted a retrospective study including patients with IBC treated in the oncology department of the military hospital of Tunis between January 2015 and December 2020

Results IBCrepresented $2.7 \%$ of all BC in our population. The median age was 49 years. Invasive ductal carcinoma was reported in $98 \%$ of cases and SBR III grade in $62 \%$ of cases. Tumor was triple-negative (TN) in $22 \%$ and Her2neu overexpressed in $42 \%$ of cases. The disease wasmetastaticat diagnosis in $25 \%$ of patients. Metastasis were more frequently localized in brain(25\%), liver(11\%) and lungs (33\%). Neoadjuvant sequential chemotherapy (CT) and mastectomy with axillary lymph nodes dissection and locoregional radiotherapy was delivered in all localized cases.Pathological complete response was noted in $29 \%$ of these cases.Patients received adjuvant Capecitabin CT in 55\% of cases. Disease recurrence was observed in $66 \%$ of cases after a median time to progression of 15 months.In metastatic disease,FEC orTaxanes were used as first line therapy in $90 \%$ of cases.Median overall survival was 35 months for localizedand 19 months for metastatic disease.5 years desease free survival of our study was $29 \%$. Inpatients with metastatic disease at diagnosis, TN and HER2 overexpressed status and the presence of visceral crisis significantly impaired overall survival

Conclusions Treatment and therapeutic results remain limited in our country because of the lack of other therapeutic resources such as immunotherapy

\section{EPV011/\#170 ADJUVANT CHEMOTHERAPY-INDUCED AMENORRHEA IN LUMINAL BREAST CANCER PATIENTS: A STRONG PROGNOSTIC FACTOR IN TUNISIAN PREMENOPAUSAL WOMEN}

${ }^{1} \mathrm{~A}$ Zribi* ${ }^{2}{ }^{2}$ B Ben Abdallah, ${ }^{2} \mathrm{~S}$ Ben Nasr, ${ }^{3} \mathrm{~S}$ Fendri, ${ }^{4} \mathrm{~N}$ Mansouri, ${ }^{3} \mathrm{R}$ Arfaoui*, ${ }^{4} \mathrm{I}$ Mejri, ${ }^{3} \mathrm{M}$ Balti, ${ }^{3} \mathrm{~A}$ Haddaoui. ${ }^{1}$ Military Hospitalhopital Militaire de Tunis, Medical Oncology, Tunis, Tunisia; ${ }^{2}$ Military Hospitalhopital Militaire de Tunis, Medical Oncology, Tunis, Tunisia; ${ }^{3}$ Military Hospital of Tunis, Oncology, Tunis, Tunisia; ${ }^{4}$ Oncologymilitary Hospital of Tunis, Oncology, Tunis, Tunisia

\subsection{6/ijgc-2021-IGCS.78}

Objectives There has been conflicting data on the prognostic value of adjuvant chemotherapy-induced amenorrhea (ACIA) in breast cancer (BC) patients. The aim of our study was to assess prognosis value of ACIA in Tunisian premenopausal patients with luminal BC

Methods We conducted a retrospective study including premenopausalpatients with localized luminal BC treated in the oncology department of the military hospital of Tunis between January 2013 and December 2019. ACIA was defined as absence of menses for at least 6 months occurring during CT or within 3 months from the end of CT

Results 83 patients were included. Median age was 40 years. ACIA occurred in 60\% of patients: $70 \%$ had luminal $\mathrm{A}$ and $30 \%$ had luminal B BC. Patients with higher BMI were more likely to develop ACIA $(p=0.10)$. Median follow up was 67 months. Hazard Ratio for Disease-Free Survival (DFS) suggested that ACIA was associated with significant reduction in the risk of recurrence $(\mathrm{HR}=0.1, \mathrm{p}<0,001)$. ACIA was also associated to prolonged Overall Survival (OS) $(\mathrm{HR}=0.32$, $\mathrm{p}=0.032)$. OS and DFS benefit because of ACIA was associated with positive lymph nodes $(\mathrm{LN})(\mathrm{HR}=0.1, \mathrm{p}=0.003$ for $\mathrm{OS})$ and $(\mathrm{HR}=0.22, \mathrm{p}<0.001$ for $\mathrm{DFS}) . \mathrm{LN}$ involvement $(p=0.043)$, tumor size $\geq 4 \mathrm{~cm}(p=0.03)$ and ki67 $\geq 30 \%$ $(\mathrm{p}=0.08)$ were associated with lower DFS. ki67 $\geq 30 \%$ $(\mathrm{p}=0.023)$ and tumor size $\geq 5 \mathrm{~cm} \quad(\mathrm{p}=0.052)$ were associated with lower OS

Conclusions ACIA in luminal BC was significantly correlated to better OS and DFS supporting the theory of indirect endocrine effect of CT in addition to its cytotoxic effect.

\section{EPV012/\#171 ENDOCRINE THERAPY-INDUCED ALOPECIA IN PATIENTS WITH BREAST CANCER IN TUNISIA}

${ }^{1} \mathrm{~A}$ Zribi, ${ }^{2} \mathrm{~S}$ Ben Nasr, ${ }^{2} \mathrm{M}$ Ahmad, ${ }^{3} \mathrm{~S}$ Fendri, ${ }^{2} \mathrm{~N}$ Mansouri, ${ }^{3} \mathrm{R}$ Arfaoui ${ }^{*},{ }^{2}$ I Mejri, ${ }^{3} \mathrm{M}$ Balti, ${ }^{3}$ A Haddaoui. 'Military Hospitalhopital Militaire de Tunis, Medical Oncology, Tunis, Tunisia; ${ }^{2}$ Oncologymilitary Hospital of Tunis, Oncology, Tunis, Tunisia; ${ }^{3}$ Military Hospital of Tunis, Oncology, Tunis, Tunisia

\subsection{6/ijgc-2021-IGCS.79}

Objectives Despite their benefit, Endocrine therapies (ET) are known to have substantial adverse events (AEs) such as hot flashes, mood disorders and osteoarticular pain. ET induced alopecia(EIA) is less frequently noted by patients and is less reported in the literature. The aim of our study was to report ET alopecia characteristics and their influence on patient and treatment observance.

Methods We conducted a retrospective study including luminal BC patients treated in the oncology department of the military hospital of Tunis between January 2015 and December 2020. Patients treated with previous chemotherapy inducing alopecia were excluded.

Results 145 female patients were included. Median age was59 years. EIA was reported in $44 \%$ of cases. Alopecia was attributed to aromatase inhibitors in 53\% and tamoxifen in $21 \%$. Severity was grade 1 in $80 \%$ and grade 2 in the remain cases. ET discontinuation because of alopecia was noted in $6.5 \%$ of patients. Moderate improvement of alopecia wasobserved with topical minoxidil andThallium metallicum 9CH homeopathy during ET in $60 \%$ of patients.

Conclusions EIA is frequent in BC patients and should be considered to improve treatment observance and patients' quality of life. 